Підприємництво, господарство і право. - 1999. - № 7. - С. 31-32.

5. Цивільне право в Україні: курс лекцій: У 6 - ти томах. Т.1. / Р.Б. Шишка, О.Л. Зайцев, Є.О. Мічурін [та ін.]; за заг. ред. Р.Б. Шишки та В.А. Кройтора. - Харків : Національний університет внутрішніх справ, 2004.

6. Серова О.А. Теоретико-методологические и практические проблемы классификации юридических лиц современного гражданского права России: Монография [Текст] / Ольга Александровна Серова. - М. : Издательство «Юрист », 2011 . - 328 с.

7. Сліпченко С.О. Особисті немайнові правовідносини щодо оборотоздатних об'єктів : монографія [Текст] / Святослав Олександрович Сліпченко. - Х. : Діса плюс, 2013. - 552 с.

8. Зеліско А.В. Правовий статус споживчих товариств : монографія [Текст] / Алла Володимирівна Зеліско // Івано-Франківськ, Сімик. - 2011. 184 с. ; Зеліско А.В. Правове регулювання статусу споживчих товариств : послідовність чи хаотичність? / А.В. Зеліско // Збірник наукових праць викладачів Юридичного інституту Прикарпатського національного університету імені Василя Стефаника : Прикарпатський національний університет імені Василя Стефаника, 2012. - C. 91-100.

9. Венедиктова I.В. Методологічні засади охоронюваних законом інтересів у приватному праві : монографія [Текст] / Ірина Валентинівна Венедиктова. - Х. : Нове Слово, 2011. - 260 с.

10. Сойфер Т.В. Концепция некоммерческих организаций в российском гражданском праве : автореф. на соиск. уч. степени д-ра юрид. наук. - Татьяна Владимировна Сойфер. - М. - 2013. - 54 с.

11. Суханов Е.А. Концепция развития законодательства о юридических лицах [Текст] / Е.А. Суханов // Журнал российского права. - 2010. - № 1. - С. 8-11.

12. Правове регулювання некомерційних організацій в Україні : монографія / [I.В. Спасибо-Фатєєва, B.I. Борисова, О.П. Печений та ін.] ; за заг. ред. І.В. Спасибо-Фатєєвої. - Х. : Право, 2013. - 480 с.

\title{
ИНФОРМАЦИОННО-АНАЛИТИЧЕСКОЕ ОБЕСПЕЧЕНИЕ ПРОТИВОДЕЙСТВИЯ ПРЕСТУПНОСТИ
}

\author{
Александр ИГНАТОВ, \\ кандидат юридических наук, старший научный сотрудник, \\ доцент кафедры уголовного права и криминологии \\ Одесского государственного университета внутренних дел
}

\section{Summary}

The article is sanctified to the problems of the information-analytic providing of counteraction of criminality. Exactly this constituent plays a major role in intercommunication and co-operation between different components, levels, elements of mechanism of counteraction of criminality. Taking into account entering of humanity into an informative era, objective lag of law-enforcement activity from development of criminality, the role of this direction of activity increases constantly. With the purpose of decision of tasks and optimization of process of collection, storage, generalization, analysis of criminology information, necessary for the operative estimation of criminogenic situation, forming of criminology prognoses and planning of criminallypreventive activity, conceptual directions of perfection of the information-analytic providing of counteraction of criminality are certain, in particular offered, worked out and created by means of control system by the databases of MySQL relational database.

Key words: criminology information, information-analytic providing, criminality, counteraction, database.

\section{Аннотация}

Статья посвящена проблемам информационно-аналитического обеспечения противодействия преступности. Именно данная составляющая играет важнейшую роль во взаимосвязи и взаимодействии между различными компонентами, уровнями, элементами механизма противодействия преступности. Учитывая вступление человечества в информационную эру, объективное отставание правоохранительной деятельности от развития преступности, роль данного направления деятельности постоянно возрастает. С целью решения задач и оптимизации процесса сбора, структуризации, хранения, обобщения, анализа криминологической информации, необходимой для оперативной оценки криминогенной обстановки, формирования криминологических прогнозов и планирования уголовно-превентивной деятельности определены концептуальные направления совершенствования информационно-аналитического обеспечения противодействия преступности. В частности, предложена разработанная и созданная с помощью системы управления базами данных MySQL реляционная база данных.

Ключевые слова: криминологическая информация, информационно-аналитическое обеспечение, преступность, противодействие, база данных.

$\Pi$ остановка проблемы. Учет, моделирование и прогнозирование состояния биосоциальных систем невозможны без внедрения в работу соответствующих государственных органов электронных баз данных показателей состояния систем с представлением информации в пригодном для дальнейшего анализа и использования виде. Стандартизация, унификация информации, представляемой в таких баз данных, а также автоматизация ее сбора необходимы и для плодотворного межгосударственного сотрудничества в сфере противодействия преступности и предупреждения чрезвычайных происшествий [1, c. 301-302].
Актуальность темы исследования. Именно информационно-аналитическое обеспечение играет важнейшую роль во взаимосвязи и взаимодействии между различными компонентами, уровнями, элементами механизма противодействия преступности. Учитывая вступление человечества в информационную эру, объективное отставание правоохранительной деятельности от развития преступности, роль данного направления деятельности постоянно возрастает.

Состояние исследования. Значительный вклад в общую теорию и практику противодействия преступности сделали Г.А. Аванесов, Ю.М. Антонян, А.М. Бандурка, В.В. Голина, Л.М. Давыденко, 
И.Н. Даньшин, Т.А. Денисова, А.Н. Джужа, А.И. Долгова, В.С. Зеленецкий, А.Ф. Зелинский, А.П. Закалюк, И.И. Карпец, Я.Ю. Кондратьев, Н.Ф. Кузнецова, В.М. Кудрявцев, И.П. Лановенко, А.Н. Литвак, А.Н. Литвинов, В.В. Сташис, В.Я. Таций, В.А. Туляков, В.И. Шакун и др. Однако, несмотря на разработанность данной темы, в науке существует ряд проблем, прежде всего, связанных с отсутствием единого подхода относительно содержания противодействия преступности, его механизма, уровней, элементов и составляющих, а также их взаимодействия.

Целью и задачей статьи является исследование проблем сбора, структуризации, хранения, обобщения, анализа криминологической информации с целью оперативной оценки криминогенной обстановки, формирования криминологических прогнозов и планирования уголовнопревентивной деятельности, а также определение концептуальных направлений совершенствования информационно-аналитического обеспечения противодействия преступности.

Изложение основного материала. Информационно-аналитическое обеспечение - подструктура механизма, функционирование которой обеспечивает своевременный сбор, обобщение, анализ криминологической информации с целью оперативной оценки криминогенной обстановки, формирования криминологических прогнозов и планирования уголовно-превентивной деятельности. Эта подструктура предусматривает наличие: во-первых, аналитического центра - модератора обращения криминологической информации и ее научной обработки; во-вторых, собственно самой информационной системы в виде централизованных учетов информации - банков данных о преступлениях, их детерминанты; в-третьих, развитой инфраструктуры, методики и системы сбора информации - криминологического мониторинга. В этой области криминологической деятельности существует множество проблемных аспектов, которые концентрируются вокруг фальсификации статистических данных, учитывая ведомственные интересы правоохранительных органов, а также объективных факторов, связанных с недостатками в самой организации и содержании учетной практики. Как отмечает А. Г. Кальман, приоритетным стало направление на максимальную математизацию аналитической работы. $\mathrm{B}$ ее основу положены манипуляции со статистическими показателями, которые не воспроизводят реальное состояние противодействия преступности, а показывают только движение учетных документов о выявленных и раскрытых преступлениях, в которых достаточно четко прослеживается определенная воля и желание руководителей правоохранительных органов. В организации информационно-аналитической деятельности правоохранительных органов явно не прослеживается ориентация аналитиков на использование необходимых знаний в области криминологии, статистики, экономического анализа, организации управления в органах внутренних дел, методик изучения уровня латентной преступности, прикладного прогнозирования и т. п. [2, с. 50-51]. Такую практику, конечно, следует признать порочной, служащей только инструментом политического манипулирования и конструирования социальной реальности искусственными средствами, которые влекут ее искажение.

Не углубляясь в данную проблематику, которая, очевидно, требует самостоятельного фундаментально-прикладного монографического исследования, следует, по нашему мнению, поддержать тех ученых, которые высказывают мнение о том, что стремление Украины интегрироваться в европейское и мировое сообщество диктует необходимость применения мировых стандартов в области учета и анализа совершенных в стране преступлений [3, с. 17]. В этом аспекте обращает на себя внимание прогрессивная идея внедрения в национальную практику противодействия преступности государственной автоматизированной системы криминологической информации (далее - ГАСКИ), которая направлена на интеграцию разноведомственных подсистем учета преступлений и криминогенных факторов. По своей сути ГАСКИ концептуально должна пред- ставлять унифицированный и автоматизированный банк данных о криминологических факторах отдельных видов преступлений и иных правонарушений [4, с. 50-51]. Отдельно следует отметить то, что ГАСКИ позволит интерпретировать качественную криминологическую информацию в ее количественном выражении (а это, соответственно, открывает возможности для ее использования в ЭВМ). На сегодня учеными Национальной академии правовых наук Украины разработаны соответствующие методология и концепция указанной системы, созданы первые две базы данных. Главным критерием ГАСКИ являются криминологические факторы отдельных видов преступлений и иных правонарушений. Иными словами, построение указанной системы происходит по принципу «от преступления к детерминантам» [5, с. 157]. Признавая в целом значительный потенциал ГАСКИ, отметим целесообразность ее концептуального совершенствования в сторону увеличения прогностических возможностей. В частности, речь идет о ее информационном наполнении данными о криминогенных факторах без жесткой привязки к условиям ближайших уровней детерминации преступлений отдельных видов и преступности в целом. ГАСКИ должна быть содержательно дифференцирована и на высочайшем уровне своего информационного обобщения содержать индикаторы социальной напряженности (суицидальность, алкоголизацию, бродяжничество и т.д.), психического и физического здоровья граждан, генетико-демографическую картину, гелиогеомагнитную активность и иные данные, которые будут обеспечивать ее динамичность, адаптивность и прогностическую, упреждающую направленность, ведь главная ее цель - это не обеспечение субъектов научной деятельности полной и достоверной криминологической информацией (хотя и это, безусловно, важно), а формирование информационной модели детерминационного комплекса преступности с тем, чтобы иметь возможность вовремя отреагировать на предполагаемые изменения, осложнения.

В целях структуризации, хранения и представления статистиче- 
ских данных по уголовной активности для дальнейшего анализа нами была разработана и создана с помощью системы управления базами данных MySQL реляционная база данных [6]. Инфологическая модель этой базы, которая может быть использована для оптимизации структуры ГАСКИ, представлена на рис. 1. Эта база данных представляет собой иерархическую систему таблиц, упорядоченных и связанных между собой соответствующими связями. Каждая таблица предназначена для хранения информации об определенном аспекте или факторе преступной активности, которая представляет интерес в рамках статистического анализа: например, таблица criminals содержит информацию о преступниках, таблица victims - о жертвах преступлений, таблица crimes_criminals - об участии преступников в совершенных ими преступлениях и т. д.
Таблицы в разработанной базе данных можно разделить на два типа: самостоятельные (cases, crimes, criminals и victims) и связующие (crimes_criminals, crimes_victims, victim_criminals). Рассмотрим сначала самостоятельный тип таблиц. Таблица cases (в пер. с англ. - дела) является «корневой» для всех. Она включает, например, такие данные, как номер уголовного производства, суд, который его рассматривает, idномера преступления, преступника, жертвы и т. д. Таблица crimes (в пер. с англ. - преступления) содержит всю отчетную информацию о преступлениях, как время и место совершения, характер, статья УК Украины и т.д. Таблица criminals (в пер. с англ. - преступники) включает общие, не связанные с конкретным преступлением данные о преступниках (пол, возраст, национальность и т.д.). Аналогично, таблица victims (в пер. с англ. - жертвы) включает общую, не связанную с конкретным преступлением информацию о жертвах.

Относительно

связующего типа таблиц, то в таблице crimes criminals, как было сказано выше, содержатся данные об участии преступника в преступлении (например, мотивы или роль в групповом преступлении), то есть она связывает две самостоятельные таблицы - crimes и criminals. Еще одним примером связующей таблицы является crimes_victims. Она содержит информацию, связанную с преступлением, а также о жертве (например, количество и характер ранений головы, украденных вещей и др.) и является связующей между таблицами crimes и victims. Последний представитель связующих таблиц - criminals victims. Данные, которые связывают определенным образом преступника и жертву, содержатся в этой таблице (например, отношения с жертвой, степень близости) (рис. 1).

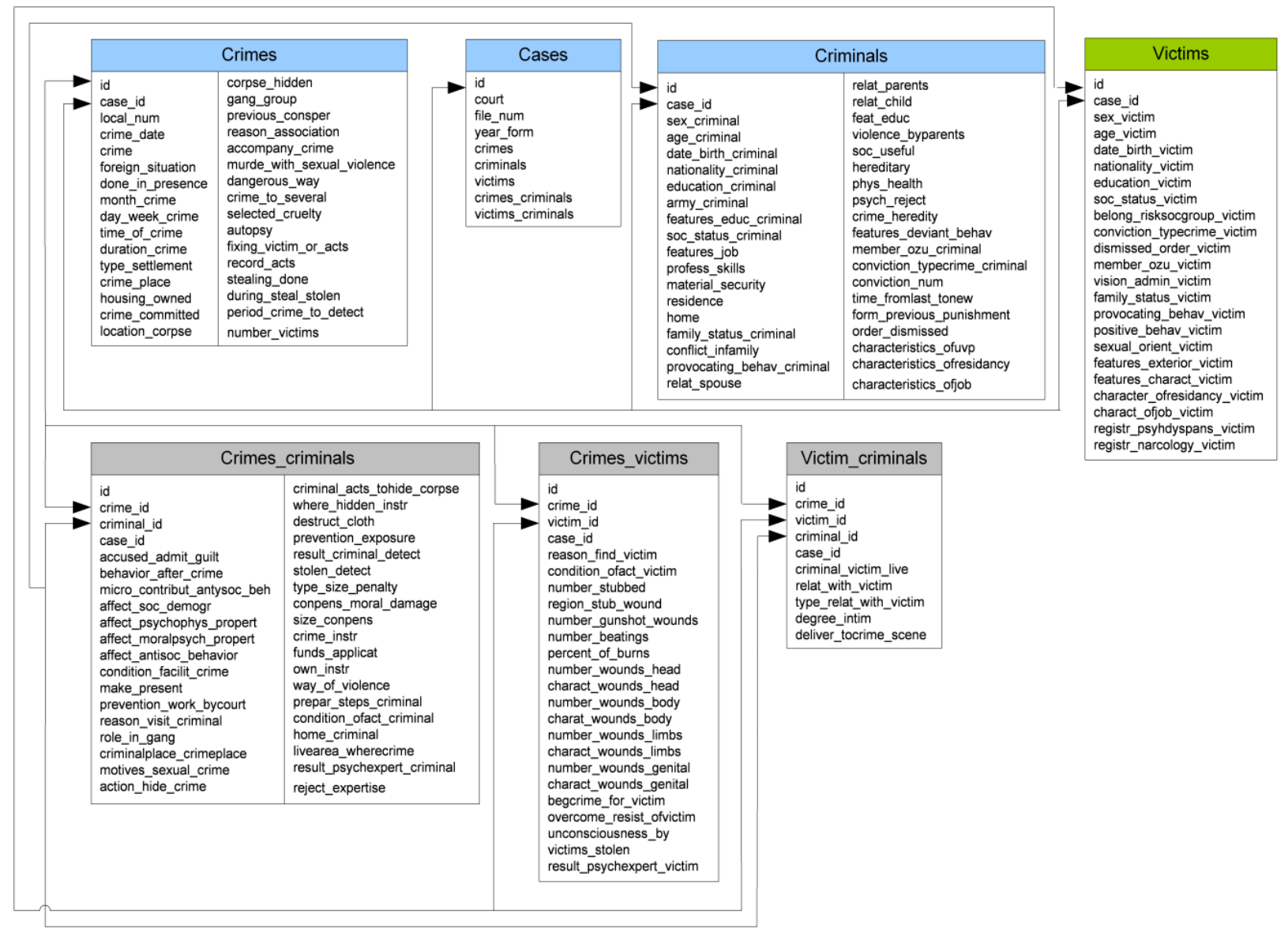

Рис. 1. Инфологическая модель реляционной базы данных, адаптированная к компьютерной обработки с использованием ресурсов системы управления базами данных MySQL 
Такая иерархическая структура обеспечивает гибкость и расширяемость базы данных: она может легко адаптироваться под новые требования или запросы путем добавление новых таблиц и связей. В то же время наряду с гибкостью база данных обеспечивает широкую функциональность: из нее одинаково просто провести как специализированную выборку по определенному критерию, интересующего исследователя или модератора системы противодействия преступности на том или ином уровне, вследствие того, что информация структурирована по отдельным таблицам, так и общий запрос всех данных для непосредственного изучения материалов уголовных отчетов, благодаря наличию связующих таблиц. При такой модели, которая показана на рисунке 1 , статистические данные содержатся в структурированном виде и с достаточно визуализированными связями.

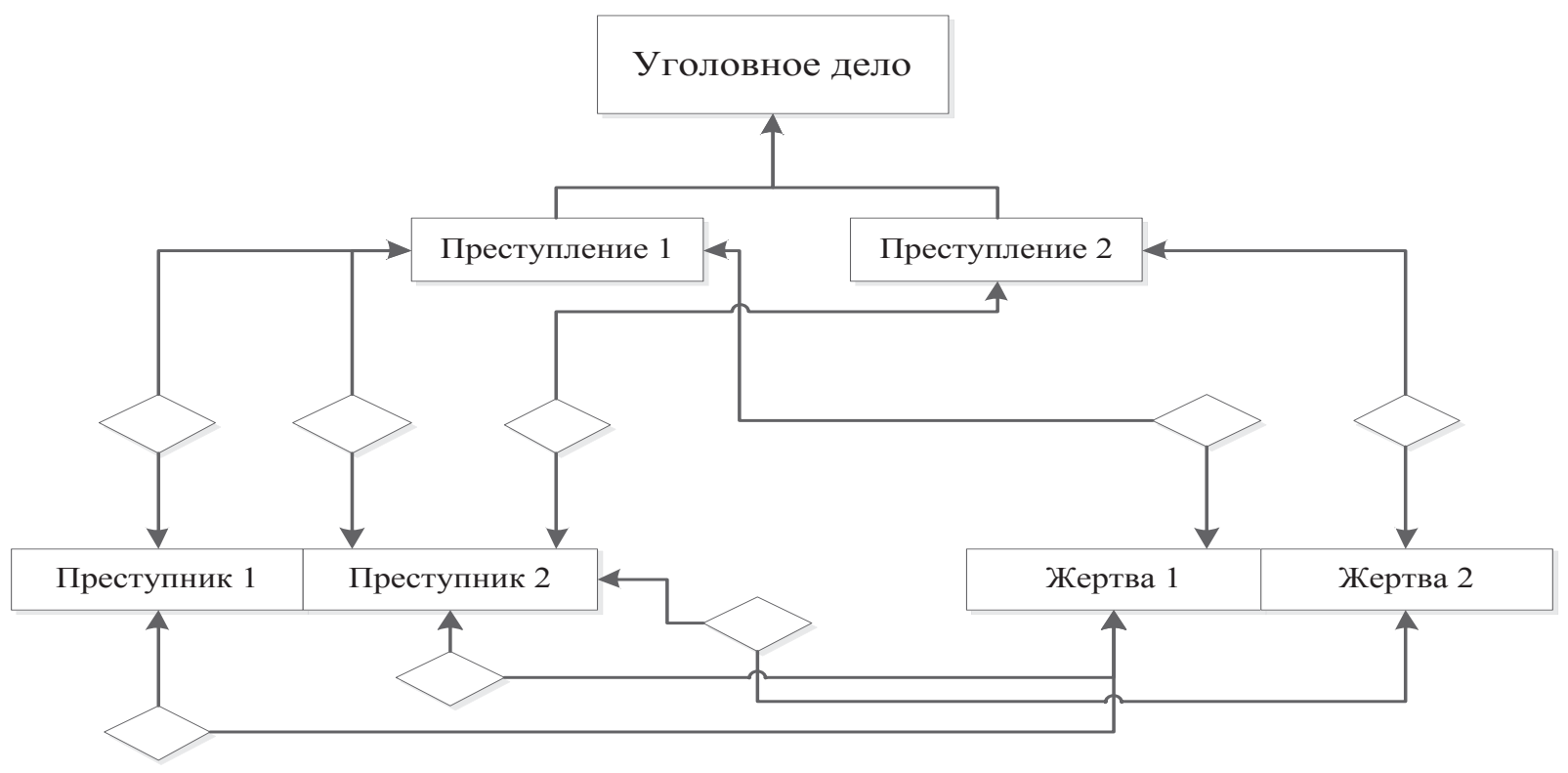

Рис. 2. Схема структуры записи в базе данных

Главным структурным элементом в созданной базе данных, которая в перспективе может быть интегрирована с ГАСКИ, является уголовное дело. С ним связываются преступления, с преступлениями - преступники, жертвы и их отношения (рис. 2).

Прямоугольниками на рис. 2 показаны самостоятельные элементы записи, а ромбами - их связующие элементы, которые содержатся в самостоятельных и связующих таблицах. В результате такого упорядочивания статистических данных в базе данных достигается простота и эффективность доступа к ним для дальнейшего анализа, например, для построения сложной выборки и т. д. Также благодаря тому, что база данных содержит достаточно широкий спектр сведений, становится возможным построение в дальнейшем различных математических прогнозов на основе выборок из указанной базы. Так, например, при анализе статистики дат совершения преступлений можно выявить некоторую закономерность и построить прогноз на основании вре- менных рядов, что позволит с определенной вероятностью предотвращать преступления. Следует отметить, что построение математических прогнозов и статистический анализ возможны только при условии наличия достаточно большого (не менее тысячи дел) общего объема занесенных в базу данных о преступлениях одного типа (отдельный состав преступления). В таком случае, полученные результаты и вероятностную оценку этих результатов можно считать валидными. В зависимости от того, связь между какими аспектами или факторами преступной активности будет устанавливаться, могут применяться различные методы анализа и прогнозирования. Причем, предложенная система предусматривает расширение количества и качества уже заложенных методов анализа данных. Для конечного пользователя системой задача анализа данных и прогнозирования максимально автоматизирована.

Система управления базой данных - это лишь средство, которое помога- ет удобнее изучать и преобразовывать данные. Если рассматривать задачу анализа данных и прогнозирования в целом, то она состоит из нескольких этапов. Первый этап заключается в том, чтобы представить данные в системе для машинного обучения, этап предварительного анализа. Выполняется кодирование качественных признаков и нормализация данных. Второй этап - это непосредственно машинный (программный) анализ данных. Если среди данных есть скрытые взаимосвязи, корреляция между признаками, структурные связи, то в таком случае возникает задача уменьшения размерности входных данных. На тот или иной аспект преступления влияют не все факторы, указанные в анкете одновременно, а лишь некоторый набор этих факторов. Эта проблема особенно ярко себя проявляет в ситуации, когда обрабатывается большое количество разреженных данных. В предложенной системе (базе) заложен классический путь решения этой задачи - метод анализа главных 
компонентов (PСA) [7], а также метод нейросетевого сжатия данных [8]. На третьем этапе эксперт должен оценить полученные результаты.

Указанные аспекты создают предпосылки для внедрения электронных баз данных (на основе вышеописанной) как составляющих ГАСКИ в учреждения правоохранительных органов как с целью накопления, систематизации и оперативного использования наиболее полной информации о преступности в стране (регионе) в целом, или в отношении того или иного вида преступлений, так и с целью оперативной обработки имеющейся в конкретных производствах информации об отдельных преступлениях с целью выдвижения следственных версий. В дальнейшем при наполнении базы (которая, как представляется, должна располагаться на веб-сайте по принципу построения электронных систем государственных реестров) данными, целесообразно использовать временные ряды космофизических и метеорологических индексов, учета социальных показателей и иных факторов, создание инструментария для исследований: интерфейса, моделей, программ для проведения автоматизированного прогнозирования и поддержки принятия решений соответствующими специалистами.

Вместе с тем следует отметить, что указанную модель информационного обеспечения противодействия преступности не следует рассматривать как самодостаточную. Неотъемлемым операционным компонентом наполнения ГАСКИ, а также обеспечения своевременной информацией субъектов противодействия преступности является криминологический мониторинг. Е. Н. Блаживский, в своей фундаментальной работе, посвященной криминологическому мониторингу, обоснованно, на наш взгляд, определяет его как открытую, динамичную, нелинейную постоянно действующую систему наблюдения, содержанием которой являются осуществляемые на научной основе сбор, анализ, обобщение и оценка криминологически значимых явлений, процессов и состояний объектов в разные периоды времени с целью повышения (поддержания) эффективности управления противодействием преступности; специализированную постоянно функционирующую информационную технологию обеспечения эффективного криминологического анализа, прогнозирования и контроля в системе противодействия преступности, средство поддержания ее адаптивности, интеграции с социальной средой $[9$, с. 20,34$]$. Спецификация параметров мониторинговой деятельности с потребностями постоянного информационного обеспечения системы противодействия преступности требует внедрения в нее соответствующих целей, которые должны быть вычленены из содержания объекта превентивного воздействия в структуре механизма уголовно-превентивной практики, а также параметров поиска, сбора и обработки информации, обеспечивающих насыщение системы сведениями про как можно более широкий спектр факторов детерминации отдельных видов преступного поведения в контексте более широкой гаммы детерминант преступности, проявляющиеся через индикаторы социальной напряженности, уровень тревожности, агрессивности и т. д.

Выводы. Эффективное информационно-аналитическое обеспечение противодействия преступности на сегодня не возможно без решения ряда проблем, касающихся сбора, структуризации, хранения, обобщения, анализа криминологической информации с целью оперативной оценки криминогенной обстановки, формирования криминологических прогнозов и планирования превентивной деятельности. Стандартизация, унификация криминологической информации, а также автоматизация ее сбора необходимы не только для эффективного функционирования механизма противодействия преступности в рамках отдельной страны, но и для межгосударственного сотрудничества в данной сфере. Это обуславливает острую необходимость создания и внедрения соответствующих универсальных электронных баз данных (например, на основе вышеописанной). При этом следует учитывать, что информационно-поисковая и аналитическая деятельность должна осуществляться с учетом требований общей либерально-гуманистической направленности противодействия преступности и аккумуляции сведений о социокультурной динамике.
Список использованной литературы:

1. Григорьев П.Е. Информационные технологии мониторинга биосоциальных систем / [П.Е. Григорьев, В.В. Бычков, А.Н. Игнатов и др.] // Обчислювальний інтелект (результати, проблеми, перспективи) : матеріали I Міжнародної науково-технічної конференції (10-13 травня 2011 р., Черкаси). - Черкаси : Маклаут, 2011. С. 301-302.

2. Кальман О.Г. Проблеми інформаційно-аналітичного забезпечення протидії злочинності / О.Г. Кальман, О.В. Вавренок // Вісник Національної академії прокуратури. 2009. - № 1. - C. 49-54.

3. Бандурка А.М. Преступность в Украине: причины и противодействие: монография / А.М. Бандурка, Л.М. Давыденко. - Х. : Основа, 2003. - 368 с.

4. Закалюк А.П. Курс сучасної української кримінології: теорія і практика : у 3 кн. Кн. 3 / А.П. Закалюк. - К. : Видавничий Дім «Ін Юре», 2007. - 317 с.

5. Орлов Ю.В. Кримінологічна експертиза нормативно-правових актів i ix проектів: науково-методичне забезпечення : монографія / Ю.В. Орлов. - Сімферополь : КРП «Видавництво «Кримнавчпеддержвидав»», 2010. - 266 с.

6. Игнатов А.Н. Информационнотехнологические аспекты учета и прогнозирования преступности / А.Н. Игнатов, П.Е. Григорьев, А.В. Оленчук, Асанов Э.Э. // Известия научно-технического общества «Кахак». Спецвыпуск. - Алматы, 2011. - № 4(34). - С. 77-81.

7. Topological grammars for data approximation / Gorban A.N. , Sumner N.R., and Zinovyev A.Y // Applied Mathematics Letters, Volume 20, Issue 4, 2007. - P. 382-384.

8. Yoshua Bengio. Learning deep architectures for AI / Yoshua Bengio // Foundations and Trends in Machine Learning, Volume 2, Number 1, 2009. $127 \mathrm{p}$.

9. Блажівський Є.М. Моніторинг протидії злочинності в Україні : монографія / Є.М. Блажівський. - Х. : Золота миля, 2013. -372 с. 